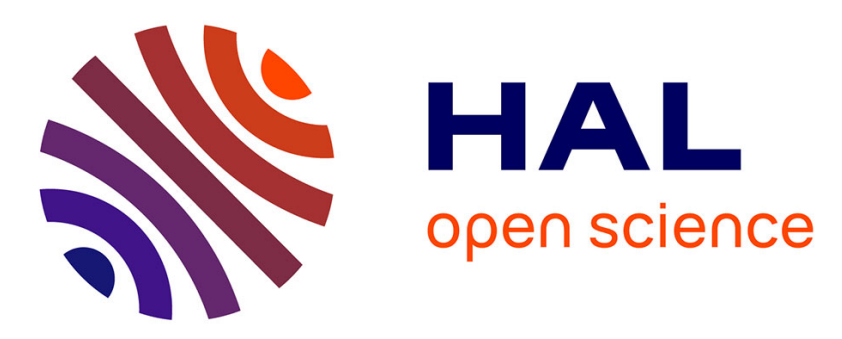

\title{
Structural discrimination of double-walled carbon nanotubes by chiral diporphyrin nanocalipers
}

Gang Liu, Yukie Saito, Daisuke Nishio-Hamane, Ajoy K. Bauri, Emmanuel Flahaut, Takahide Kimura, Naoki Komatsu

\section{- To cite this version:}

Gang Liu, Yukie Saito, Daisuke Nishio-Hamane, Ajoy K. Bauri, Emmanuel Flahaut, et al.. Structural discrimination of double-walled carbon nanotubes by chiral diporphyrin nanocalipers. Journal of Materials Chemistry A, 2014, vol. 2 ( $\mathrm{n}^{\circ}$ 44), pp. 19067-19074. 10.1039/c4ta04407j . hal-01138706

\section{HAL Id: hal-01138706 https://hal.science/hal-01138706}

Submitted on 2 Apr 2015

HAL is a multi-disciplinary open access archive for the deposit and dissemination of scientific research documents, whether they are published or not. The documents may come from teaching and research institutions in France or abroad, or from public or private research centers.
L'archive ouverte pluridisciplinaire HAL, est destinée au dépôt et à la diffusion de documents scientifiques de niveau recherche, publiés ou non, émanant des établissements d'enseignement et de recherche français ou étrangers, des laboratoires publics ou privés. 


\section{OATAO}

\section{Open Archive TOULOUSE Archive Ouverte (OATAO)}

OATAO is an open access repository that collects the work of Toulouse researchers and makes it freely available over the web where possible.

This is an author-deposited version published in : http://oatao.univ-toulouse.fr/ Eprints ID : 13665

To link to this article : DOI:10.1039/c4ta04407j

URL : http://dx.doi.org/10.1039/c4ta04407j

\section{To cite this version :}

Liu, Gang and Saito, Yukie and Nishio-Hamane, Daisuke and Bauri, Ajoy K. and Flahaut, Emmanuel and Kimura, Takahide and Komatsu, Naoki Structural discrimination of double-walled carbon nanotubes by chiral diporphyrin nanocalipers. (2014) Journal of Materials Chemistry. A, vol. 2 ( ${ }^{\circ}$ 44). pp. 19067-19074. ISSN 2050-7488

Any correspondance concerning this service should be sent to the repository administrator: staff-oatao@ listes-diff.inp-toulouse.fr 


\title{
Structural discrimination of double-walled carbon nanotubes by chiral diporphyrin nanocalipers $\uparrow$
}

\author{
Gang Liu, ${ }^{a}$ Yukie Saito, ${ }^{b}$ Daisuke Nishio-Hamane, ${ }^{c}$ Ajoy K. Bauri, ${ }^{d}$ Emmanuel Flahaut, ${ }^{e}$ \\ Takahide Kimura $^{a}$ and Naoki Komatsu ${ }^{* a}$ \\ In this contribution, we demonstrate the separation of double-walled carbon nanotubes (DWNTs) by host- \\ guest methodology. New chiral diporphyrin nanocalipers with a longer spacer ( 1.9 nm) consisting of \\ carbazole-pyrene-carbazole are rationally designed as a host on the basis of the previous chiral \\ diporphyrin nanocalipers with carbazole-anthracene-carbazole spacer $(\sim 1.4 \mathrm{~nm})$. The chiral \\ nanocalipers are found to recognize the diameter of DWNTs to make diameter distribution much \\ narrower. In addition, the extracted carbon nanotubes (CNTs) exhibited circular dichroism (CD) after \\ removal of the chiral nanocalipers and dissolution in water in the presence of achiral surfactant.
}

\section{Introduction}

Carbon nanotubes (CNTs) have been in the forefront of nanomaterial research in the past decades due to their unique physical and chemical properties. According to the number of layers, CNTs have been classified into the following three kinds: single-walled CNTs (SWNTs), double-walled CNTs (DWNTs), and multi-walled CNTs (MWNTs). While extensive fundamental studies and practical applications have been performed on SWNTs, ${ }^{1-5}$ DWNTs have attracted significant interest because of their superior properties, including characteristics of both SWNTs and MWNTs. ${ }^{6-10}$

Since the properties of CNTs are known to correlate with their structures, ${ }^{\mathbf{1}}$ the structural uniformity of CNTs in terms of number of walls, diameter, length, roll-up index or $(n, m)$, and/ or handedness is preferable for fine applications. Although various methods for targeting separation and selective synthesis have been developed for SWNTs, ${ }^{\mathbf{1 1 - 1 3}}$ DWNTs are far left behind from SWNTs in spite of their utility. The direct synthesis of DWNTs $^{\mathbf{1 4}}$ results in significant quantity of SWNTs and MWNTs

${ }^{a}$ Department of Chemistry, Shiga University of Medical Science, Seta, Otsu 520-2192, Japan.E-mail: nkomatsu@belle.shiga-med.ac.jp; Fax: +81-77-548-2405; Tel: +81-77548-2102

${ }^{b}$ Graduate School of Agricultural and Life Sciences, The University of Tokyo, 1-1-1 Yayoi, Bunkyo-ku, Tokyo 113-8657, Japan

${ }^{c}$ The Institute for Solid State Physics, The University of Tokyo, 5-1-5 Kashiwanoha, Chiba 277-8581, Kashiwa, Japan

${ }^{d}$ Bio-Organic Division, Bhabha Atomic Research Center, Trombay, Mumbai 400085, India

${ }^{e}$ Université de Toulouse; UPS, INP, CNRS; Institut Carnot Cirimat, 118, route de Narbonne, F-31062 Toulouse Cedex 9, France

$\dagger$ Electronic supplementary information (ESI) available: Fluorescence spectra of the complex (Fig. S1), diameter distribution of SWNTs (Fig. S2 and S3), absorption spectra of the extracted CNTs (Fig. S4), synthetic procedure, ${ }^{1} \mathrm{H}$ and ${ }^{13} \mathrm{C}$ NMR and ESI-MS spectra of nanocalipers. See DOI: $10.1039 / \mathrm{c} 4$ ta04407j accompanied with DWNTs and a broad diameter distribution of DWNTs. ${ }^{15-18}$ The separation of DWNTs has been limited to the density gradient ultracentrifugation (DGU) method, ${ }^{19-24}$ except for the methods using chromatography ${ }^{25}$ and biopolymers. ${ }^{26,27}$ Despite the superior properties of DWNTs, the separation of DWNTs has been rarely reported probably because of the wider range of diameters and number of walls included in the assynthesized DWNTs. In addition, optically active DWNTs have not been reported yet, though many optically active SWNTs have been identified.11,12 This motivates us to design chiral diporphyrin nanocalipers to discriminate the handedness of DWNTs.

Herein, we report on the separation of DWNTs through molecular recognition by chiral diporphyrin nanocalipers with a larger cavity than the previous ones applied to the separation of SWNTs. ${ }^{28}$ Since an advantage of our host-guest methodology for CNT separation lies in the flexibility in molecular design of the host for targeting CNTs, we rationally designed a wider nanocaliper with carbazole-pyrene-carbazole spacer having 1.9 $\mathrm{nm}$ in length for DWNT separation, as shown in Scheme 1.

\section{Results}

\subsection{Synthesis of the chiral diporphyrin nanocalipers}

The chiral diporphyrin nanocalipers are synthesized through Suzuki-Miyaura coupling reaction, as shown in Scheme 1. The long spacer consisting of three aromatic units (carbazole-pyrene-carbazole) was directly prepared by coupling the commercial pyrene-2,7-diboronate with 3-bromo-9-octyl-9H-carbazole in $62 \%$ yield. After bromination, the resulting bromide was allowed to react with two chiral porphyrins through SuzukiMiyaura coupling reaction to give $(R)$ - or $(S)$-1, respectively, in $\sim 40 \%$ yield. The products were fully identified by absorption, circular dichroism (CD), ESI-MS, and ${ }^{1} \mathrm{H}$ and ${ }^{13} \mathrm{C}$ NMR spectroscopies (Fig. 1 and ESI $\dagger$ ). 


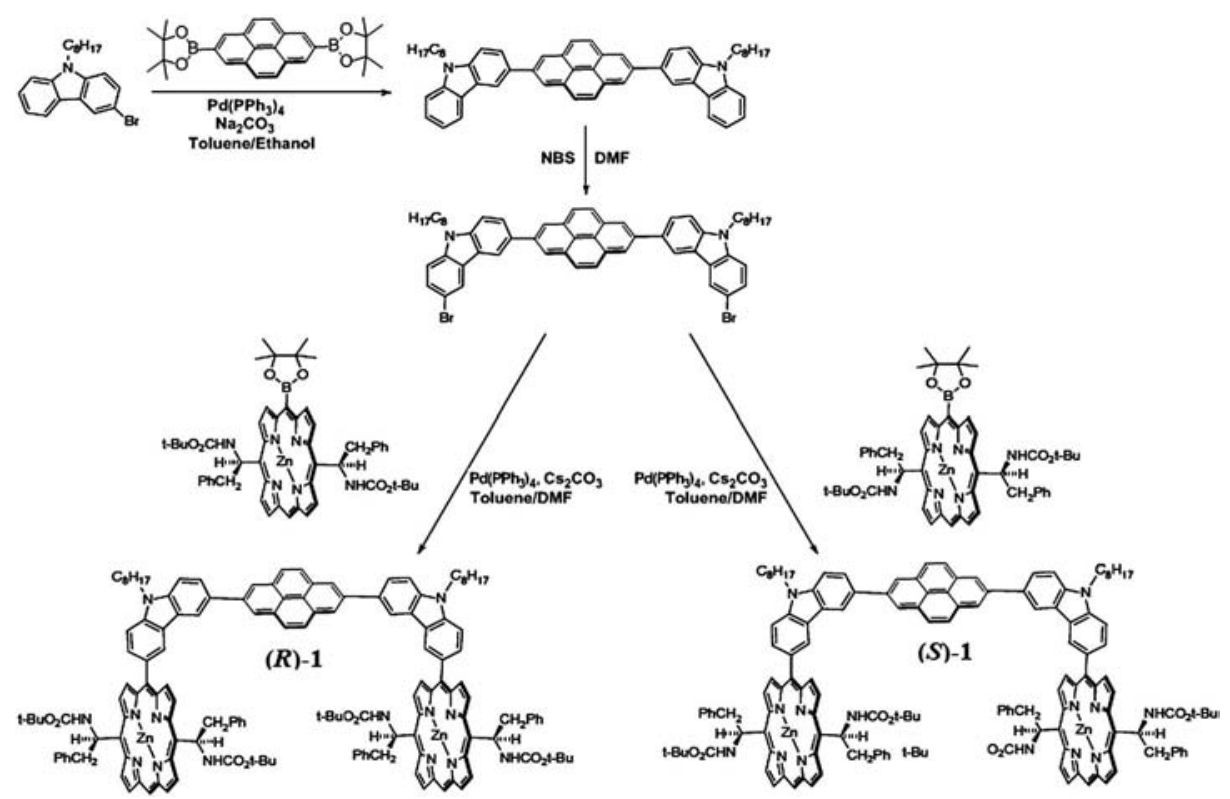

Scheme 1 Synthesis of chiral diporphyrin nanocalipers $(R)-$ and $(S)-1$.

\subsection{Extraction of DWNTs with chiral diporphyrin nanocalipers}

The DWNTs used in this work were prepared by catalytic chemical vapor deposition (CCVD), as reported previously. ${ }^{14}$ According to the literature, high-resolution transmission electron microscopy (HR-TEM) showed that the as-prepared sample consists of $77 \%$ DWNTs, $18 \%$ SWNTs, and 5\% triple-walled CNTs (TWNTs). The diameter of DWNTs ranged from $1.23 \mathrm{~nm}$ to $3.23 \mathrm{~nm}$ for outer tubes and from $0.53 \mathrm{~nm}$ to $2.53 \mathrm{~nm}$ for inner tubes (Fig. 4). ${ }^{14}$ In the extraction, DWNTs and chiral nanocalipers $(R)$ - or $(S)-\mathbf{1}$ in methanol were bath-sonicated and centrifuged for two days (see Experimental section in detail). The resulting greenish extract was quite stable without sedimentation even after four months. The extract was then subjected to UV-vis-NIR, CD, and fluorescence spectroscopy measurements to confirm the existence of the complex between DWNTs and $\mathbf{1 .}$
In the absorption spectra shown in Fig. 1a, the $\mathrm{Q}$ bands of the porphyrins in the nanocalipers 1 are broadened and redshifted from $554 \mathrm{~nm}$ to $565 \mathrm{~nm}$ upon complexation with DWNTs. In addition, a new peak appears at $441 \mathrm{~nm}$, which may be caused by the red shift of the Soret band. These spectral changes may be attributed to the $\pi-\pi$ and/or $\mathrm{C}-\mathrm{H}-\pi$ interactions between the nanocalipers and CNTs. ${ }^{29}$ The upward shift of the baseline and the appearance of a broad peak from $700 \mathrm{~nm}$ to $900 \mathrm{~nm}$ indicate that a significant amount of CNTs was extracted into the solution phase and present as stable complexes with nanocalipers in the extract. The complexation of CNTs and $\mathbf{1}$ is further confirmed by the quenching of fluorescence from the porphyrins (Fig. S1†) and the enhanced Cotton effects in CD spectra (Fig. 1b) due to the fixation of the two chiral porphyrins. ${ }^{30}$

As shown in the scanning electron microscopy (SEM) and scanning transmission electron microscopy (STEM) images (Fig. 2), almost all the strings are individualized without a)

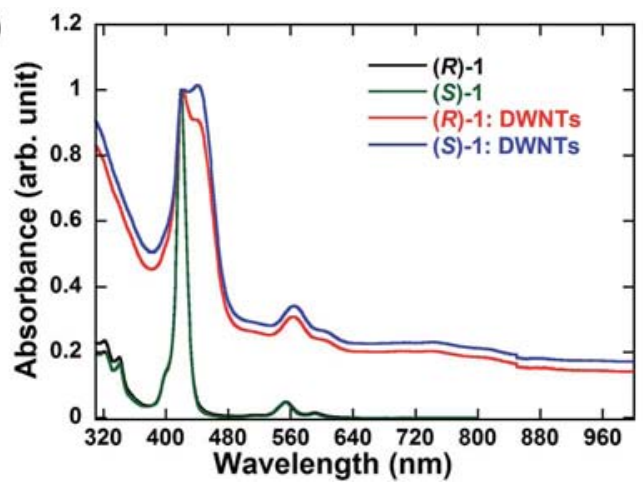

b)

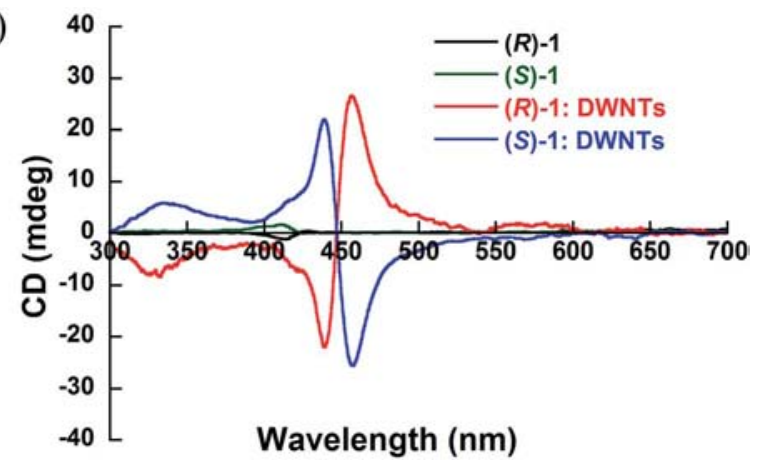

Fig. 1 Absorption (a) and CD spectra (b) of $(R)$ - and (S)-1 before and after extraction. CD spectra of nanocalipers and nanocaliper-DWNT complexes were normalized at the absorbance of $419 \mathrm{~nm}$ and $441 \mathrm{~nm}$, respectively. 
a)

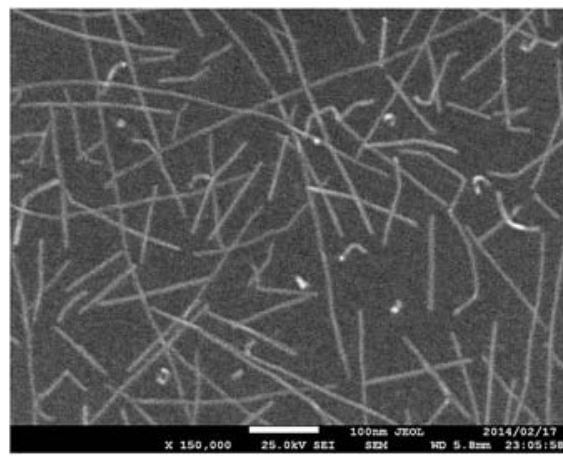

b)

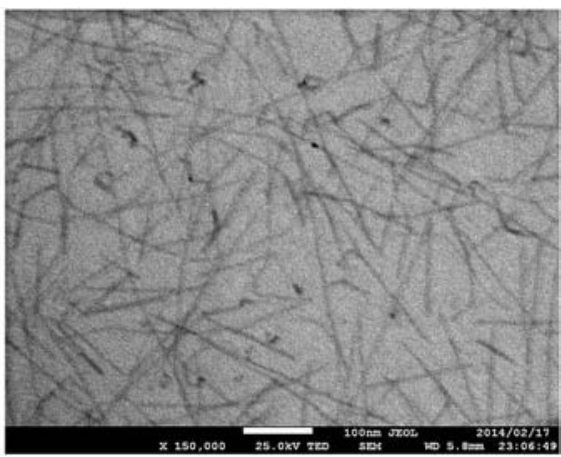

Fig. 2 SEM (a) and STEM (b) images of the CNT complexes with 1. The two images were taken at the same region.

bundling in the whole scanned region, indicating the high stability of the CNT complex with 1. Direct evidence of the complexation between nanocalipers and DWNT is given by the HR-TEM images, which will be discussed below.

\subsection{Diameter distribution of DWNTs before and after the extraction}

In order to evaluate the recognition ability of the nanocalipers 1 toward the CNT structure, we measured HR-TEM of the extract, Raman spectra after washing out the nanocalipers from the extracted CNT complexes, and absorption and CD spectra after dissolving the washed sample in $\mathrm{D}_{2} \mathrm{O}$ (see Experimental section in detail). In the absorption spectra, the observed bands are not so sharp as those of SWNTs used in our previous studies, ${ }^{28,31,32}$ probably because the large abundance of DWNTs significantly increases the variety in the tubular carbon structures. Since the absorption spectra are concluded to have little valuable information for structural determination of CNTs before and after the extraction, the spectra are shown in ESI (Fig. S4 †) along with the possible interpretation based on the Kataura plot. ${ }^{1}$

2.3.1 HR-TEM analysis of the extract. For determination of the enriched diameter range through the extraction, we measured HR-TEM of the extract with 1. Three typical images of the extracted DWNTs are shown in Fig. 3. In these images, the CNTs are wrapped with some materials, which are considered to be nanocalipers as in the case of SWNTs. ${ }^{28}$ In addition, the two walls are discriminated clearly to measure the diameters of the inner and outer tubes in these DWNTs. The analysis of 81 isolated CNTs allowed us to determine the distribution in the number of walls and the diameters of the inner and outer tubes (Fig. 4).

Although SWNTs are found in the images, TWNTs included at $5 \%$ before the extraction disappear after the extraction, indicating that nanocalipers $\mathbf{1}$ cannot form a stable complex with TWNTs because of their large diameters. The distribution of the number of walls before and after the extraction is shown in Fig. 4a. The abundance of SWNTs and DWNTs slightly increases from $18 \%$ and $77 \%$ to $20 \%$ and $80 \%$, respectively, because TWNTs are not extracted as mentioned above. This phenomenon implies that the nanocalipers cannot discriminate SWNTs and DWNTs and may recognize diameters of the CNTs. Therefore, the ratio between the SWNTs and DWNTs after the separation should be influenced by that before the separation.

In terms of diameter selectivity, a remarkable diameter shift through the extraction is indicated by the histogram shown in Fig. $4 \mathrm{~b}-\mathrm{d}$. DWNTs with $1.25-2.75 \mathrm{~nm}$ outer tube diameters are the major components $(90 \%)$ in the raw DWNTs, as indicated in Fig. $4 \mathrm{~b}$. After the extraction, DWNTs with much narrower diameter range, i.e., $1.25-1.75 \mathrm{~nm}$, increase from $21 \%$ to $84 \%$. DWNTs with the diameter of $1.50 \pm 0.25 \mathrm{~nm}$ are concluded to be a)

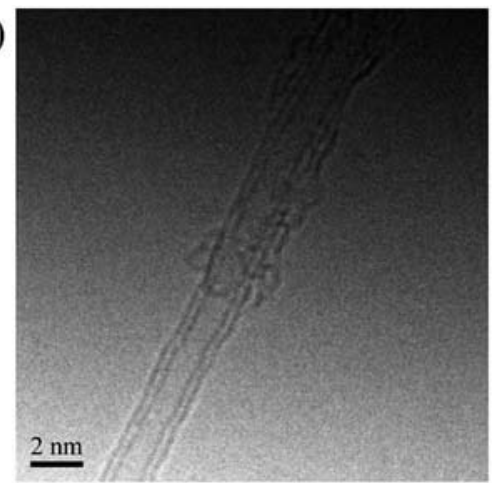

b)

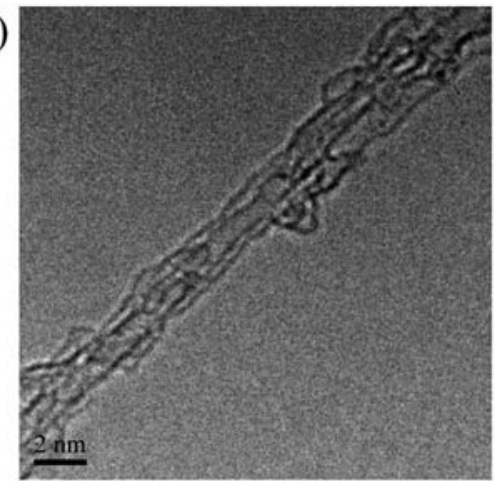

c)

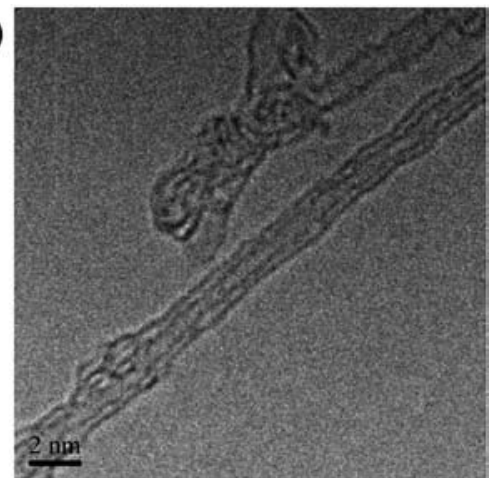

Fig. 3 Typical HR-TEM images of DWNTs wrapped with nanocalipers 1. The respective outer and inner diameters are (a) $1.71 \mathrm{and} 1.02 \mathrm{~nm}$, (b) 1.58 and $0.91 \mathrm{~nm}$, and (c) 1.47 and $0.76 \mathrm{~nm}$. 
a)

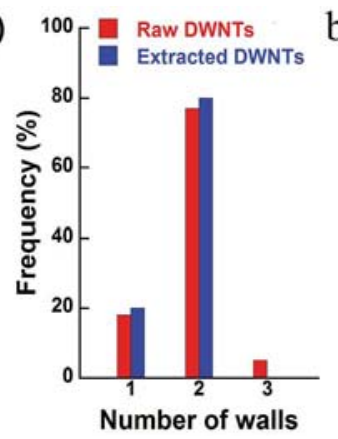

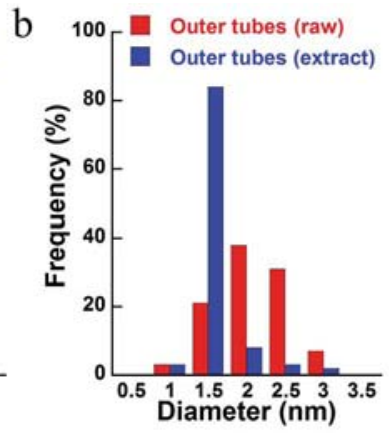
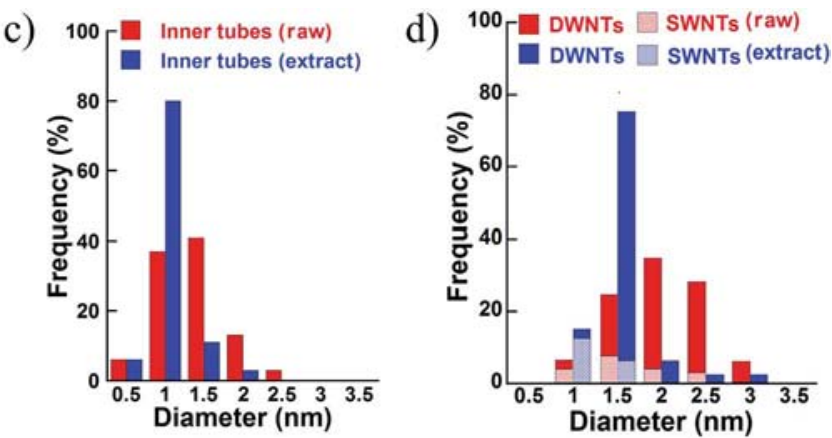

Fig. 4 Frequency of SWNTs, DWNTs and TWNTs (a), diameter distribution of outer (b) and inner (c) tubes in DWNTs, and CNTs (SWNTs + DWNTs) (d) before and after the extraction with $(R)-1$. The distribution in the number of walls and in the diameter of raw sample is adapted from ref. 14 .

highly enriched through the extraction due to the preference of the nanocalipers 1 for the diameter range, as we intended through rational design of the host molecule.

Since $20 \%$ of the CNTs found in the HR-TEM images are SWNTs, their diameter range is also compared before and after the extraction. As shown in Fig. $4 \mathrm{~d}$ and $\mathrm{S} 2, \dagger$ the diameter range of the SWNTs became much narrower from $0.75-2.75 \mathrm{~nm}$ to $0.75-1.75 \mathrm{~nm}$ through the extraction as in the case of the outer tube mentioned above. The histogram of the SWNT diameters with narrower steps $(0.2 \mathrm{~nm})$ shown in Fig. S3at indicates that the diameter range of $1.10 \pm 0.10 \mathrm{~nm}$ is highly enriched after the extraction. The broad diameter range of SWNTs before the extraction is made to be much narrower and be shifted to relatively small diameter through the extraction.

Since the nanocalipers $\mathbf{1}$ are considered to recognize the diameters of not only the outer tubes of DWNTs but also SWNTs, the diameter distribution of CNTs irrespective of number of layers is compared, as shown in Fig. $4 \mathrm{~d}$ and S3b. $\dagger$ Although most of the extracted DWNTs are in the range of 1.50 $\pm 0.25 \mathrm{~nm}$ in diameter as shown in Fig. $4 \mathrm{~b}$, CNTs with $0.75-1.75$ $\mathrm{nm}$ in Fig. 4d or 1.0-1.8 nm in Fig. S3b $\dagger$ are enriched in the extracted CNTs (SWNTs + DWNTs).

2.3.2 Raman analysis of the extract. After the methanol extracts of DWNTs with $(R)$ - and $(S)$-1 were concentrated, the resulting black solids were washed with THF and pyridine several times to thoroughly remove the nanocalipers from the complex. More than $70 \%$ of the chiral nanocalipers were recovered and reused after purification. The washed samples were subjected to Raman spectroscopy at the excitation of 488 , 633 , and $785 \mathrm{~nm}$ to determine the diameter range enriched through the extraction. Since the DWNTs extracted with $(R)$ - and $(S)-1$ exhibited almost the same spectra, the spectra before and after the extraction with $(R)-\mathbf{1}$ are shown in Fig. 5, and the results are summarized in Table 1 . The diameter of CNTs is calculated by the following eqn (1);

$$
\omega_{\mathrm{RBM}}=223.5 / d+12.5
$$

where $\omega_{\mathrm{RBM}}$ is the Raman shift $\left(\mathrm{cm}^{-1}\right)$ of the radial breathing mode (RBM) and $d$ is the diameter (nm) of CNTs. ${ }^{33}$

At the excitation of $488 \mathrm{~nm}$, a prominent spectral change is observed in the lower frequency region through the extraction with nanocalipers 1 . As shown in Fig. 5a, the peaks in the region of $164-217 \mathrm{~cm}^{-1}$ corresponding to the diameters of 1.09-1.48 $\mathrm{nm}$ are significantly enriched through the extraction. Adjacent peaks at 141 and $228 \mathrm{~cm}^{-1}$ corresponding to the diameters of 1.74 and $1.04 \mathrm{~nm}$, respectively, decrease in intensity or relative abundance. Although most of the peaks increase in the higher frequency region, they are assigned to be the inner tubes in the DWNTs, because their diameters are smaller than $0.8 \mathrm{~nm}$. Similar phenomena are observed in the spectra excited at 633 and $785 \mathrm{~nm}$ (Fig. 5b and c, respectively). The drastic increase in the intensity is observed in the peaks at 170 and $198 \mathrm{~cm}^{-1}$ corresponding to 1.42 and $1.21 \mathrm{~nm}$, respectively, at $633 \mathrm{~nm}$
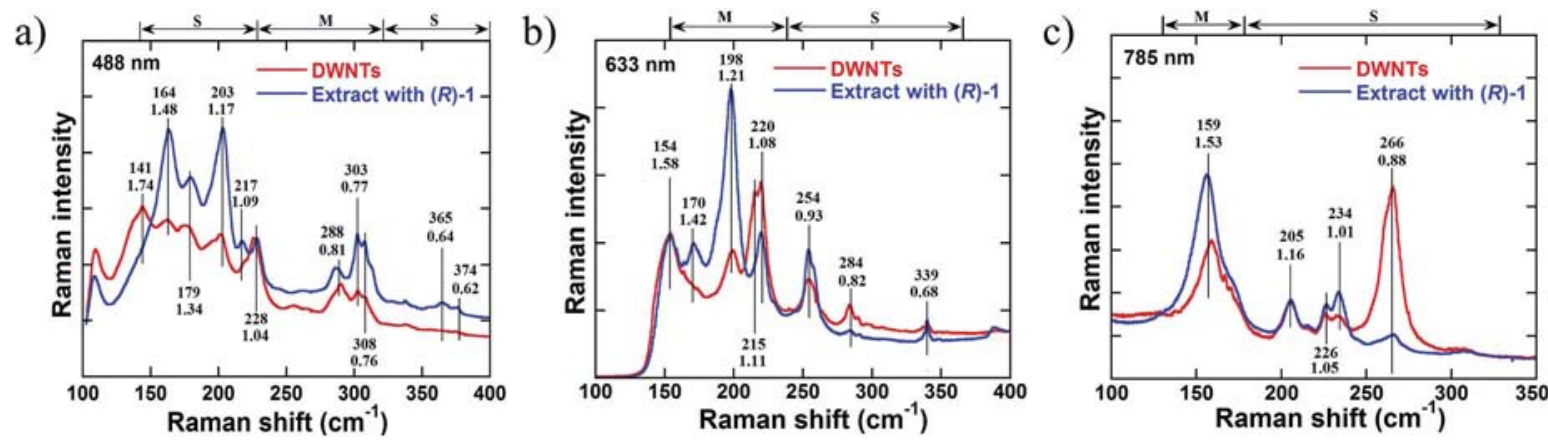

Fig. 5 Raman spectra of DWNTs before and after the extraction with $(R)-1$ in the RBM. Wave number $\left(\mathrm{cm}^{-1}\right)$ and the corresponding diameter $(\mathrm{nm})$ are indicated at each peak. $\mathrm{S}$ and $\mathrm{M}$ at the top of the spectra indicate semiconducting and metallic, respectively. 
Table 1 Comparison of the Raman intensity of CNTs before and after extraction $^{a}$

\begin{tabular}{llll}
$\begin{array}{l}\text { Excitation } \\
\text { wavelength/nm }\end{array}$ & 488 & 633 & 785 \\
\hline $\begin{array}{l}\text { Increased } \\
\text { diameters }^{b} / \mathrm{nm}\end{array}$ & $1.09-1.48(\mathrm{~S})$ & $1.20(\mathrm{M}), 1.42(\mathrm{M})$ & $1.53(\mathrm{M})$ \\
$\begin{array}{l}\text { Decreased } \\
\text { diameters }^{c} / \mathrm{nm}\end{array}$ & $1.04(\mathrm{M}), 1.74$ & $1.10(\mathrm{M}), 1.08(\mathrm{M})$ & $0.88(\mathrm{~S})$
\end{tabular}

${ }^{a} \mathrm{M}$ and $\mathrm{S}$ in parentheses denote metallic and semiconducting, respectively. ${ }^{b}$ Diameters or diameter range of CNTs increased in their Raman intensity. ${ }^{c}$ Diameters of CNTs decreased in their Raman intensity.

excitation, and at $159 \mathrm{~cm}^{-1}$ corresponding to $1.53 \mathrm{~nm}$ at $785 \mathrm{~nm}$ excitation. The reduction in the peak intensity is detected at 215 and $220 \mathrm{~cm}^{-1}$ (1.11 and $1.08 \mathrm{~nm}$, respectively) at $633 \mathrm{~nm}$ excitation and at $266 \mathrm{~cm}^{-1}(0.88 \mathrm{~nm})$ at $785 \mathrm{~nm}$ excitation.

From the summary of the results in the Raman analyses shown in Table 1, we can conclude that the diameter range of 1.1-1.5 $\mathrm{nm}$ is enriched through the extraction with nanocalipers 1. The enriched diameter range determined by HR-TEM as mentioned above (Fig. $\mathrm{S} 3 \mathrm{~b}_{\dagger}^{\dagger}$ ) is $1.0-1.8 \mathrm{~nm}$, which will be narrowed by applying the results of the Raman analysis (Table 1 ). At the small diameter region, the border between increase and decrease is distinct at $1.1 \mathrm{~nm}$ as shown in Table 1 , reducing the above diameter range from $1.0-1.8 \mathrm{~nm}$ to $1.1-1.8 \mathrm{~nm}$. At the large diameter region, CNTs with $1.7 \mathrm{~nm}$ decrease their relative abundance, as shown in Table 1. Because of lack in Raman information between $1.5-1.7 \mathrm{~nm}$ in diameter, the enriched diameter range is concluded to be 1.1-1.7 $\mathrm{nm}$, taking into consideration the results in both the HR-TEM and the Raman measurements.

\subsection{Optical enrichment of extracted CNTs}

The optical enrichment of the extracted CNTs is confirmed by CD spectra of the SDBS- $\mathrm{D}_{2} \mathrm{O}$ dispersion of the washed CNTs after the extraction, as shown in Fig. 6. The CNTs extracted with $(R)$ - and $(S)$-1 exhibit almost symmetrical CD, indicating that the extracted CNTs are optically active.

Clear CDs are observed at the regions of 550-600 nm, 600$680 \mathrm{~nm}$, and $680-770 \mathrm{~nm}$, which correspond to the diameter ranges of the extracted CNTs shown in Table 2, based on the

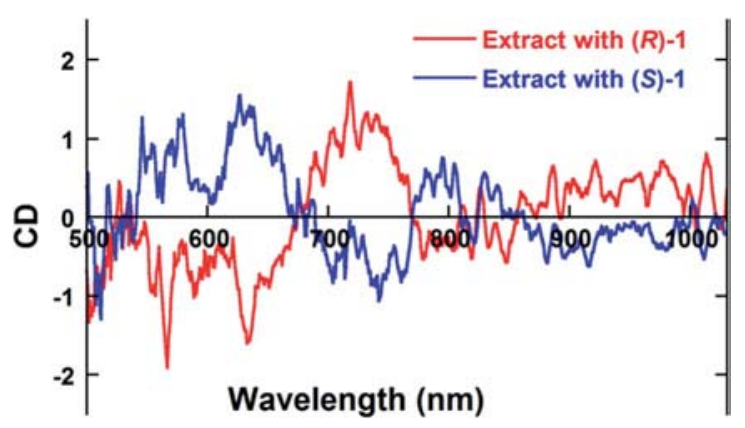

Fig. 6 CD spectra of DWNTs extracted with (R)- and (S)-1.
Table 2 Diameter range of CNTs responsible to the CD

\begin{tabular}{|c|c|c|c|}
\hline $\begin{array}{l}\text { Range/nm } \\
\text { in CD } \\
\text { observation }\end{array}$ & $\begin{array}{l}\text { Corresponding } \\
\text { energy range/eV }\end{array}$ & $\begin{array}{l}\text { Corresponding } \\
\text { diameter range/nm } \\
\text { (optical transition) }^{a}\end{array}$ & Assignment \\
\hline $550-600$ & $2.1-2.3$ & $\begin{array}{l}\sim 0.7\left(E_{22}^{\mathrm{S}}\right) \\
1.0-1.2\left(E_{22}^{\mathrm{M}}\right) \\
1.4-1.6\left(E_{33}^{\mathrm{S}}\right)\end{array}$ & $\begin{array}{l}\text { Inner tube } \\
\text { SWNT } \\
\text { Outer tube }\end{array}$ \\
\hline $600-680$ & $1.8-2.1$ & $\begin{array}{l}0.7-0.9\left(E_{22}^{\mathrm{S}}\right) \\
1.1-1.3\left(E_{22}^{\mathrm{M}}\right) \\
1.5-1.8\left(E_{33}^{\mathrm{S}}\right)\end{array}$ & $\begin{array}{l}\text { Inner tube } \\
\text { SWNT } \\
\text { Outer tube }\end{array}$ \\
\hline $680-770$ & $1.6-1.8$ & $\begin{array}{l}0.8-1.0\left(E_{22}^{\mathrm{S}}\right) \\
1.3-1.5\left(E_{22}^{\mathrm{M}}\right) \\
>1.8\left(E_{33}^{\mathrm{S}}\right)\end{array}$ & $\begin{array}{l}\text { Inner tube } \\
\text { Outer tube } \\
\text { Outer tube }\end{array}$ \\
\hline
\end{tabular}

${ }^{a}$ The italic diameter range indicates that the tubes in the range may contribute to the CD more than those in the other ranges.

Kataura plot. ${ }^{1}$ Although a much smaller number of CNTs are theoretically possible to exhibit a higher intensity of CD than much more abundant CNTs, we would assume that the CD intensity is proportional to the abundance of the optically active CNTs to interpret the result of the CD.

For the CDs in the range of 550-600 nm (Table 2), semiconducting outer tubes with 1.4-1.6 nm are considered to be more responsible than semiconducting inner tubes with $\sim 0.7$ $\mathrm{nm}$ and metallic SWNTs with 1.0-1.2 nm because of their abundance shown in Fig. 4c and d. In the range of 600-680 nm, the inner tubes with $0.7-0.9 \mathrm{~nm}$, SWNTs with $1.1-1.3 \mathrm{~nm}$, and the outer tubes with 1.5-1.8 $\mathrm{nm}$ are included in their most abundant regions of the inner tube (0.75-1.25 nm, Fig. 4c), SWNTs (1.0-1.2 nm, Fig. S3a $\dagger$ ), and the outer tube (1.25-1.75 nm, Fig. 4b), respectively. However, the metallic SWNTs with 1.1-1.3 nm should be less responsible to the $\mathrm{CD}$ in the region because of the much smaller abundance of SWNTs than DWNTs shown in Fig. 4a and metallic tubes than semiconducting ones theoretically. Since the chiral diporphyrin nanocalipers can recognize the helical structures of the outer tubes in DWNTs, the CD in the region of 600-680 nm may have originated mostly from the outer tubes with $1.5-1.8 \mathrm{~nm}$. If the helicity of the inner tubes has some influence from that of the outer tubes upon the DWNT synthesis, optically active inner tubes may occur indirectly through the optical resolution of the outer tubes.

In the range of 680-770 $\mathrm{nm}$, inner tubes with $0.8-1.0 \mathrm{~nm}$ and outer tubes with 1.3-1.5 $\mathrm{nm}$ are still in the abundant diameter regions as indicated in Fig. $4 \mathrm{c}$ and b, respectively, though outer tubes having more than $1.8 \mathrm{~nm}$ diameter are out of the range (Fig. 4b). Therefore, the CD in the region of 680-770 $\mathrm{nm}$ can be attributed to the semiconducting inner tubes with $0.8-1.0 \mathrm{~nm}$ and/or the metallic outer tubes with 1.3-1.5 nm. If the aforementioned helical correlation between the outer and inner tubes is not so strong in DWNTs, the metallic outer tubes with 1.3-1.5 $\mathrm{nm}$ are concluded to contribute mainly to the CD in the region of $680-770 \mathrm{~nm}$. Due to much higher abundance of DWNTs than SWNTs (Fig. 4a), the metallic outer tubes with 1.3- 
$1.5 \mathrm{~nm}$ are considered to exhibit CD in much higher intensity than the metallic SWNTs with 1.1-1.3 nm mentioned above.

From the above discussion based on the CD (Fig. 6 and Table 2), we can conclude that the optically active forms of DWNTs are most probably obtained through molecular recognition with chiral diporphyrin nanocalipers.

\section{Discussion}

In order to understand the diameter preference of nanocalipers 1 toward CNTs, we carried out molecular modeling calculations (molecular mechanics) for the $1: 1$ complex between $(R)-\mathbf{1}$ and a SWNT with diameter of $1.0 \mathrm{~nm}$ (Fig. 7a), and DWNTs with outer tube diameters of 1.5 and $2.0 \mathrm{~nm}$ (Fig. $7 \mathrm{~b}$ and c, respectively). The energy-minimized structures shown in Fig. 7 indicate that nanocalipers $\mathbf{1}$ are somewhat flexible to accept different diameters of CNTs. In all the complex structures, there are $\pi-\pi$ interactions between CNT surface and porphyrin or pyrene to stabilize the complexes, as indicated by blue arrows in Fig. 7. In addition, $\mathrm{C}-\mathrm{H}-\pi$ interactions between carbazole in the spacer and the CNT surface improve the stability in the complexes (red arrows in Fig. 7). Although the same numbers of these interactions exist in all the complexes of 1 with CNTs, the shape of the host molecule in these complexes and the distances in these interactions are not exactly the same, resulting in differences in the complex stability.

For the SWNT with diameter of $1.0 \mathrm{~nm}$, the corresponding complex shown in Fig. 7a is considered to be less stable, because the pyrene moiety and the adjacent single bonds are bent significantly to accommodate the SWNT with much smaller diameter than the cavity size. The degree in the deformation of the nanocalipers is quantified by the dihedral angle between the two porphyrins and the distance between the two carbon atoms bound to the pyrene moiety as shown in Fig. 7a (Table 1). In this case, the dihedral angle is made to be $26^{\circ}$ and the $\mathrm{C}-\mathrm{C}$ distance becomes $9.97 \AA$. The bending of the pyrene moiety, shortening the $\mathrm{C}-\mathrm{C}$ distance, makes the dihedral angle between two porphyrins larger and the cavity smaller to accommodate the small diameter SWNT.
Table 3 The dihedral angle of the two porphyrins and the $\mathrm{C}-\mathrm{C}$ distance indicated in Fig. $7 a$

\begin{tabular}{lccc}
\hline Diameter of CNT/nm & 1.0 & 1.5 & 2.0 \\
Dihedral angle/ $/^{\circ}$ & 26 & 10 & 42 \\
C-C distance/A & 9.97 & 9.99 & 9.96
\end{tabular}

Significant deformation of the nanocalipers $\mathbf{1}$ is also observed in the case of DWNT with outer tube diameter of 2.0 $\mathrm{nm}$ (Fig. 7c). In contrast to Fig. 7a, the cavity of the nanocalipers is made to be open to accept the DWNT with $2.0 \mathrm{~nm}$ in diameter, as shown in Fig. 7c. The degree of the deformation is larger in Fig. 7c than that in Fig. 7a; that is, the dihedral angle and $\mathrm{C}-\mathrm{C}$ distance become $42^{\circ}$ and $9.96 \AA$, respectively (Table 3).

On the other hand, the host molecule accommodates the DWNT with $1.5 \mathrm{~nm}$ without any distinct strain, as shown in Fig. 7b. The two porphyrins are nearly in parallel with the dihedral angle of only $10^{\circ}$ and the pyrene is flat with longer $\mathrm{C}-\mathrm{C}$ distance of $9.99 \AA$. The order in the degree of deformation in these complexes estimated from Table 3, DWNT $(2.0 \mathrm{~nm}) / \mathbf{1}>$ SWNT $(1.0 \mathrm{~nm}) / \mathbf{1} \gg \operatorname{DWNT}(1.5 \mathrm{~nm}) / \mathbf{1}$, correlates with that in the abundance of CNTs after the extraction as shown in Fig. $4 \mathrm{~d}$. This indicates that the diameters of CNTs are discriminated on the basis of the stability of the complex. In addition, left- and right-handed ( $M$ - and $P$-) structures ${ }^{12,34}$ of the DWNTs may be discriminated by the difference in the stability between the diastereomers; $(R)-\mathbf{1} /(M)$-DWNT and $(R)-\mathbf{1} /(P)-\mathrm{DWNT}$, and $(S)-\mathbf{1} /$ $(M)$-DWNT and $(S)-\mathbf{1} /(P)$-DWNT.

\section{Conclusions}

Based on the previous research on the separation of SWNTs with chiral diporphyrins, we rationally designed and synthesized new chiral diporphyrin nanocalipers with a much longer spacer consisting of carbazole-pyrene-carbazole $(\sim 1.9 \mathrm{~nm})$ for the separation of DWNTs. As designed, the chiral nanocalipers are found to discriminate the diameter of DWNTs; DWNTs with 1.25-1.75 $\mathrm{nm}$ in diameter are highly enriched through the extraction with the chiral diporphyrin nanocalipers. CD is also

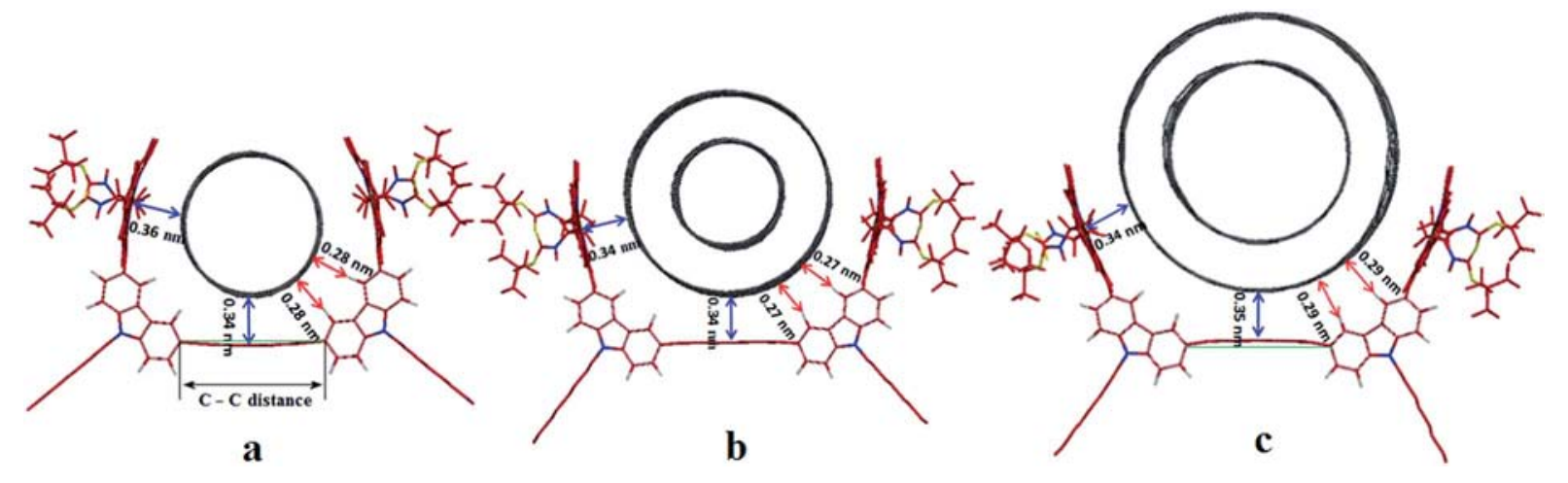

Fig. 7 Computer-generated molecular modeling of the complex structures of chiral diporphyrin nanocalipers 1 with SWNT with a diameter of $1.0 \mathrm{~nm}(\mathrm{a})$, and DWNTs with outer tube diameter of $1.5 \mathrm{~nm}$ (b) and $2.0 \mathrm{~nm}$ (c). Blue and red arrows indicate $\pi-\pi$ and $\mathrm{C}-\mathrm{H}-\pi$ interactions, respectively. C-C distance indicated in (a) is compared with those in (b) and (c) in Table 3. 
observed in the extracted CNTs. The diameters of the experimentally increased and decreased CNTs correlate with the degree of deformation or stability of the complexes on the basis of the computer generated complex structures.

\section{Experimental section}

\section{Extraction of DWNTs with nanocalipers}

Chiral nanocalipers $(R)$ - or $(S)-\mathbf{1}(10 \mathrm{mg})$ and DWNTs $(10 \mathrm{mg})$ in methanol $(40 \mathrm{~mL})$ were bath-sonicated at $20{ }^{\circ} \mathrm{C}$ for $36 \mathrm{~h}$. After centrifugation of the resulting suspension at $50400 \mathrm{~g}$ for $45 \mathrm{~h}$, the supernatant was poured for UV-vis-NIR, fluorescence, CD, HR-TEM, SEM, and STEM measurements. After concentration of the supernatant, the residual solid was washed with THF and pyridine several times until the porphyrin Soret band disappeared in the UV-vis spectra of the washings. The thoroughly washed DWNTs $(0.3 \mathrm{mg})$ were analyzed with Raman spectroscopy at excitation of 488,633 , and $785 \mathrm{~nm}$. The solid sample was dispersed in $\mathrm{D}_{2} \mathrm{O}(10 \mathrm{~mL})$ in the presence of SDBS $\left(10 \mathrm{mg} \mathrm{mL}^{-1}\right)$ by tip-sonication in a rosette cooling cell ${ }^{35}$ for $1.5 \mathrm{~h}$ at $0^{\circ} \mathrm{C}$. After centrifugation at $136000 \mathrm{~g}$ for $40 \mathrm{~min}$, the upper layer (about $85 \%$ ) of the supernatant was poured and subjected to UV-visNIR and CD measurements. For the dispersion of the raw DWNTs, tip-sonication was carried out for 40 min under the same conditions, followed by centrifugation at $543000 \mathrm{~g}$ for $30 \mathrm{~min}$.

\section{Acknowledgements}

The authors thank Prof. Yasushi Kawai (Nagahama Institute of Bio-Science and Technology) for allowing us to use CD spectropolarimeter, Mr Haruo Hosoda (Bruker Daltonics k.k.) for analyzing 1 with ESI-MS (micrOTOFII) spectroscopy. HR-TEM was performed using facilities of the Institute for Solid State Physics, the University of Tokyo. This work was financially supported by Grant-in-Aid for Scientific Research (S) (no. 24221009), Grant-in-Aid for Scientific Research on Priority Areas (no. 22016005), Grant-in-Aid for Scientific Research (B) (no. 23350062), the Kurata Memorial Hitachi Science and Technology Foundation, and Adaptable and Seamless Technology Transfer Program through Target-driven R\&D (JST). G. L. acknowledges Japan Society for the Promotion of Science (JSPS) for providing him with a postdoctoral fellowship (ID no. P13339).

\section{Notes and references}

1 H. Kataura, Y. Kumazawa, Y. Maniwa, I. Umezu, S. Suzuki, Y. Ohtsuka and Y. Achiba, Synth. Met., 1999, 103, 2555.

2 M. Ouyang, J.-L. Huang and C. M. Lieber, Acc. Chem. Res., 2002, 35, 1018.

3 J. M. Schnorr and T. M. Swager, Chem. Mater., 2011, 23, 646. 4 A. D. Franklin, Nature, 2013, 498, 443.

5 R. H. Baughman, A. A. Zakhidov and W. A. D. Heer, Science, 2002, 297, 787.

6 K. Tanaka, H. Aoki, H. Ago, T. Yamabe and K. Okahara, Carbon, 1997, 35, 121.
7 H. Kurachi, S. Uemura, J. Yotani, T. Nagasako, H. Yamada, T. Ezaki, T. Maesoba, R. Loutfy, A. Moravsky, T. Nakazawa, S. Katagiri and Y. Saito, International Display Workshop Proceedings, 2001, 1237.

8 Y. A. Kim, H. Muramatsu, T. Hayashi, M. Endo, M. Terrones and M. S. Dresselhaus, Chem. Phys. Lett., 2004, 398, 87.

9 T. Natsuki, T. Hayashi and M. Endo, Appl. Phys. A, 2006, 83, 13.

10 M. Endo, H. Muramatsu, T. Hayashi, Y. A. Kim, M. Terrones and M. S. Dresselhaus, Nature, 2005, 433, 476.

11 N. Komatsu and F. Wang, Materials, 2010, 3, 3818.

12 G. Liu, F. Wang, X. Peng, A. F. M. M. Rahman, A. K. Bauri and N. Komatsu, in Handbook of carbon nano materials, ed. F. D'Souza and K. M. Kadish, World Scientific, 2012, p. 203.

13 J. R. Sanchez-Valencia, T. Dienel, O. Gröning, I. Shorubalko, A. Mueller, M. Jansen, K. Amsharov, P. Ruffieux and R. Fasel, Nature, 2014, 512, 61.

14 E. Flahaut, R. Bacsa, A. Peigney and C. Laurent, Chem. Commun., 2003, 1442.

15 H. Qi, C. Qian and J. Liu, Nano Lett., 2007, 7, 2417.

16 E. Flahaut, A. Peigney, C. Laurent and A. Rousset, J. Mater. Chem., 2000, 10, 249.

17 T. Yamada, T. Namai, K. Hata, D. N. Futaba, K. Mizuno, J. Fan, M. Yudasaka, M. Yumura and S. Iijima, Nat. Nanotechnol., 2006, 1, 131.

18 T. Sugai, H. Yoshida, T. Shimada, T. Okazaki and H. Shinohara, Nano Lett., 2003, 3, 769.

19 S. Yang, A. N. Parks, S. A. Saba, P. L. Ferguson and J. Liu, Nano Lett., 2011, 11, 4405.

20 A. A. Green and M. C. Hersam, Nat. Nanotechnol., 2009, 4, 64. 21 A. A. Green and M. C. Hersam, ACS Nano, 2011, 5, 1459.

22 J. Y. Huh, A. R. H. Walker, H. W. Ro, J. Obrzut, E. Mansfield, R. Geiss and J. A. Fagan, J. Phys. Chem. C, 2010, 114, 11343. 23 D. A. Tsyboulski, Y. Hou, N. Fakhri, S. Ghosh, R. Zhang, S. M. Bachilo, M. Pasquali, L.-C. Chen, J. Liu and R. B. Weisman, Nano Lett., 2009, 9, 3282.

24 R. Fleurier, J.-S. Lauret, E. Flahaut and A. Loiseau, Phys. Status Solidi B, 2009, 246, 2675.

25 K. E. Moore, M. Pfohl, F. Hennrich, V. S. K. Chakradhanula, C. Kuebel, M. M. Kappes, J. G. Shapter, R. Krupke and B. S. Flavel, ACS Nano, 2014, 8, 6756.

26 H. Nie, H. Wang, A. Cao, Z. Shi, S.-T. Yang, Y. Yuan and Y. Liu, Nanoscale, 2011, 3, 970.

27 J. H. Kim, M. Kataoka, Y. A. Kim, D. Shimamoto, H. Muramatsu, T. Hayashi, M. Endo, M. Terrones and M. S. Dresselhaus, Appl. Phys. Lett., 2008, 93, 223107.

28 G. Liu, F. Wang, S. Chaunchaiyakul, Y. Saito, A. Bauri, T. Kimura, Y. Kuwahara and N. Komatsu, J. Am. Chem. Soc., 2013, 135, 4805.

29 G. Liu, A. F. M. M. Rahman, S. Chaunchaiyakul, T. Kimura, Y. Kuwahara and N. Komatsu, Chem.-Eur. J., 2013, 19, 16221.

30 V. V. Borovkov, G. A. Hembury and Y. Inoue, Acc. Chem. Res., 2004, 37, 449.

31 F. Wang, K. Matsuda, A. F. M. M. Rahman, T. Kimura and N. Komatsu, Nanoscale, 2011, 3, 4117. 
32 X. Peng, N. Komatsu, S. Bhattacharya, T. Shimawaki, S. Aonuma, T. Kimura and A. Osuka, Nat. Nanotechnol, 2007, 2, 361.

33 S. M. Bachilo, M. S. Strano, C. Kittrell, R. H. Hauge, R. E. Smalley and R. B. Weisman, Science, 2002, 298, 2361.
34 X. Peng, F. Wang, A. K. Bauri, A. F. M. M. Rahman and N. Komatsu, Chem. Lett., 2010, 39, 1022.

35 T. Yasumitsu, G. Liu, J.-M. Leveque, S. Aonuma, L. Duclaux, T. Kimura and N. Komatsu, Ultrason. Sonochem., 2013, 20, 37. 